\title{
Internalized HIV-Stigma, Mental Health, Coping and Perceived Social Support among People Living with HIV/AIDS in Aizawl District-A Pilot Study
}

\author{
Zoengpari Gohain, Mary Ann L. Halliday \\ Department of Psychology, Mizoram University, Aizawl, India \\ Email: zoengpari@gmail.com
}

Received 1 September 2014; revised 26 September 2014; accepted 14 October 2014

Copyright (C) 2014 by authors and Scientific Research Publishing Inc.

This work is licensed under the Creative Commons Attribution International License (CC BY). http://creativecommons.org/licenses/by/4.0/

\section{(c) (i) Open Access}

\begin{abstract}
AIDS is a global pandemic, and persons with HIV/AIDS are stigmatized throughout the world in varying degrees. The current study is a pilot study for a further in-depth study to understand the psychological implications of living with Human Immunodeficiency Virus (HIV). The study employed a quantitative approach with an aim to find out the level and prevalence of Internalized HIV Stigma (IHS) and to examine the mental health, coping strategies and perceived social support in a sample of 31 People Living with HIV/AIDS (PLWHA). Two-way classification of "Gender" (male and female) and three-way classification of "Level of IHS" (High IHS, Moderate IHS and Low IHS) on the dependent variables was employed, to elucidate the relationships between Internalized Stigma, Mental Health, Coping and perceived social support. The overall analysis revealed moderate levels of IHS (64.5\%), depression (35.5\%), and perceived social support (54.8\%), and low level of anxiety (54.8\%). It was also seen that majority (54.84\%) employed emotion-oriented coping strategy. No significant gender differences were found in IHS. However, significant gender differences were found in levels of depression ( $p<0.05)$ and Emotion-oriented coping $(p<0.05)$. Further analysis revealed that the two subscales of the IHS measure i.e. Stereotypes of HIV and Social Relationships stigma were significantly and positively correlated with anxiety $(\mathbf{p}<0.05$ and $p<$ 0.01 respectively).
\end{abstract}

\section{Keywords}

HIV/AIDS, Internalized HIV Stigma, Mental Health, Anxiety, Depression, Perceived Social Support, People Living with HIV/AIDS, Aizawl 


\section{Introduction}

Ever since the first cases of Human Immunodeficiency Virus Infection/Acquired Immunodeficiency Syndrome (HIV/AIDS) were detected in the United States in 1981, people with AIDS have been the targets of stigma. AIDS is a global pandemic, and persons with HIV/AIDS are stigmatized throughout the world in varying degrees. AIDS stigma around the world is expressed through social ostracism and personal rejection of PLWHAs, discrimination against them, and laws that deprive them of basic human rights (Mann et al., 1992; Panos Institute, 1990).

Qualitative studies in India provide rich insights into the cultural contexts of stigma and discrimination and support the presence of self or internalized stigma whereby those infected tend to accept stigmatization from others, feel guilty and justify the discriminatory behavior of others towards them (Bharat, Aggleton, \& Tyrer, 2001).

Mizoram is a small north-eastern state of India with a population of 1,097,206. Aizawl, the capital, has a population of 400,309. The Mizo society is a close-knit one, with no class distinction and no discrimination on grounds of gender. Birth of a child, marriage and death of a person in the village or community are important occasions in which the whole village or community is involved. Most of the Mizos are Christians, and their entire social life and thought-process has been transformed and guided by the Christian Church Organization. The entire society is knitted together by a peculiar code of ethics, "Tlawmngaihna” an untranslatable term meaning on the part of everyone to be hospitable kind, unselfish and helpful to others.

Mizoram, the third most affected in India, has witnessed and is experiencing the impact of HIV/AIDS. Initially, HIV transmission in Mizoram was drug-driven, heroin from the Golden Triangle being the main drug of use. The first case of HIV infection was detected in an injecting drug user (IDU) in October, 1990 and majority of HIV infection occurred among the IDUs and their partners. In 1992, the Government of Mizoram established the State AIDS Cell at the Directorate of Health Services and the Mizoram State AIDS Control Society (MSACS) came into existence in 1998 and the State AIDS Policy was approved in 1999. Since then, much effort has been given in the development and implementation of prevention and treatment strategies under targeted intervention program of the National AIDS Control Organization (NACO). According to MSACS, the number of blood tested since October, 1990 to October, 2013 is 255,453 (cumulative), and the number of HIV positive cases is 8516 (cumulative). Among the 8 districts of Mizoram, Aizawl has the second highest HIV population.

The first known cases of HIV in Mizoram were among IDUs. This population, because of their lifestyle which is perceived as voluntary, avoidable and immoral, seem to be discriminated and their HIV status considered as a form of punishment. During the years of the first few cases of HIV infection, the corpse of people who died of HIV/AIDS were wrapped in plastic bags and buried as soon as possible to avoid infection. Although much awareness has been given by the government and NGOs in educating people about the nature, causes, prevention and treatment of HIV, there are still many misconceptions about HIV/AIDS and it is still a highly feared disease.

Goffman (1963) traced the historic use of the word stigma to the Greeks, who referred to "bodily signs designed to expose something unusual and bad about the moral status of the signifier”. Merriam Webster (2011a) defines stigma as a "mark of shame or discredit, an identifying mark or characteristic," and as a "mark of guilt or disgrace” (2011b). Labeling, stereotyping, separation, status loss, and discrimination can all occur at the same time and are considered components of the stigma (Link \& Phelan, 2001).

Despite the attention given to HIV stigma, it continues to be a significant barrier to HIV prevention and treatment efforts even 30 years after the start of the epidemic. HIV/AIDS has four characteristics that account for why it is so highly stigmatized (Herek, 1999). First, it is a disease that is perceived as the bearer's responsibility because the primary modes of transmission of the infection are behaviors that are considered voluntary and avoidable. Second, it is perceived as a condition that is unalterable and fatal. Third, conditions that are contagious always have greater stigma attached to them. Fourth, conditions that are apparent to others, such as the advanced stages of AIDS, are more stigmatized. In addition, HIV-related stigma is heightened because it is "layered" upon the stigmas associated with homosexuality, drug use, and sexual promiscuity (Crawford, 1996; Novick, 1997).

Apart from outright experiences of rejection and persecution, perhaps the greatest impact of AIDS stigma is its effect on PLWHAs' willingness to disclose their health status to others (Herek, 1999). Fearing rejection and mistreatment, many PLWHAs keep their diagnosis a secret from others, which may cause them to be socially 
isolated. Such isolation, in turn, prevents them from receiving social support and can contribute to their heightened psychological distress (Crandall \& Coleman, 1992; Johnston, Stall, \& Smith, 1995). In addition, some people with AIDS internalize societal stigma, which can lead to self-loathing, self-blame, and self-destructive behaviors (Herek, 1990; Klitzman, 1997).

Internalized stigma refers to the degree to which PLWHA endorse the negative beliefs and feelings associated with HIV/AIDS about themselves (Link, 1987; Mak, Poon, Pun, \& Cheung, 2007). Internal stigma, described as felt, imagined, or self stigma, is the product of the internalization of shame, blame, hopelessness, guilt, and fear of discrimination associated with being HIV-positive (Brouard \& Wills, 2006). It is intrinsically linked with external stigma, as the fear of judgment or discrimination from others can profoundly influence the way in which people living with HIV view themselves and cope with their HIV status. Internalized HIV stigma has been found to be highly prevalent among PLWHA in Cameroon, Bangladesh and the United States of America (Jacobi et al., 2011; Hasan et al., 2012; Lee, Kochman, \& Sikkema, 2002). In Beau, Cameroon, it has been found that apart from stigma from other people, the internal stigma is the second major problem in dealing with the disease (Jacobi et al., 2011). Internalized stigma can have a profound effect on HIV prevention, treatment and care. It is likely to make an individual more sensitive to both actual and anticipated rejection and stigmatization by others, which negatively affects disclosure (Hays et al., 1993; Chesney \& Smith, 1999).

HIV/AIDS has an impact on all aspects of human life and PLWHA face tremendous psychosocial challenges, with regards to mental health, coping and social support issues. Research has shown that there is a well-established positive association between HIV-related stigma and adverse psychological outcomes including depression and anxiety (Emlet, 2007; Herek, Capitanio, \& Widaman, 2002; Prachakul, Grant, \& Keltner, 2007; Peltzer \& Ramlagan, 2011; Vyavaharkar et al., 2010). Furthermore, research findings indicate that Internalized AIDS stigmas account for a significant proportion of the variance in depression symptoms reported by PLWHA. AIDS also evokes anxiety because of its association with death (Mawar \& Paranjape, 2002). In a review by Brandt (2009), it was found that between $19 \%$ and $37 \%$ of PLWHA in Africa exhibited elevated levels of anxiety-related symptoms. A study by Perdices, Dunbar, Grunseit, Hall \& Cooper, (1992) indicated that ratings of anxiety and depression are independent of stage of HIV infection, may be in part mediated by constitutional and physical symptoms of HIV disease, but are primarily associated with the presence of psychological and psychosocial symptoms. Research findings showed that internalized HIV stigma (IHS) contributed significantly to levels of depression, anxiety, and hopelessness after controlling for the effects of key behavioral and psychosocial variables (Lee, Kochman, \& Sikkema, 2002).

Alonzo \& Reynolds (1995) described the life of an infected individual as a constant struggle to cope or manage stigma. The way in which individuals discover and disclose their HIV status to others as well as how they cope with their infection is influenced by cultural and community beliefs and values regarding causes of illness, learned patterns of response to illness, social and economic context, and social norms (Brown, Trujillo, \& Macintyre, 2001). For adults living with HIV, coping can be a key determinant of health prognosis and quality of life. In a study by Sun, Zhang and Fu (2007), the most frequently used coping style was found to be confrontation among PLWHA in China, where both acceptance-resignation and avoidance coping styles were significantly correlated with high distress.

A significant body of research suggests that social support plays a key role in managing stress associated with having HIV, resulting in better psychological outcomes among persons with HIV disease. Perceived social support has received much attention recently (Bisschop et al., 2004). Studies have found that perceived social support is associated with adjustment to and coping with HIV diagnosis (Friedland et al., 1996; Leserman et al., 1999). It is also an important resource that can enable people living with HIV/AIDS to live with their illness (Goldsmith, Brashers, Kosenko, \& O’Keefe, 2008).

The current research study is an effort to examine the under-researched concept of IHS and its role in the psychosocial aspects of PLWHA. To date, there has been no empirical study of the psychological implications of living with HIV in Mizoram. In the 50 years since Goffman's treatise, research has greatly expanded our understanding of stigma, yet much remains to be learned, and there will be new developments and challenges in the coming decades. It is believed that the field would benefit greatly from additional research on the issues such as structural factors that promote and maintain stigma, the social neuroscience of stigma, how social interactions between perceivers and stigmatized individuals impact stigma, the interrelatedness of different forms of stigma, the measurement of stigma, and stigma reduction interventions. In India, research on this important topic is gaining momentum but is still limited in scope and intervention research is almost non-existent. 
The overall consideration would not only help satisfy to achieve the theoretical and methodological considerations but would provide foundations for behavioral intervention programs and further extended studies. For this purpose, the present study was designed with the following objectives:

1) To find out the level of Internalized HIV Stigma (IHS) in the population under study.

2) To highlight the socio-demographic characteristics.

3) To examine the mental health status, coping strategies and to assess the perceived social support of PLWHA.

4) To elucidate the relationship between IHS, Mental Health, Coping strategies and Perceived Social Support among PLWHA.

\section{Methods and Procedure}

Sample: Purposive sampling procedure was followed and the final sample was 31 PLWHA (13 males and 18 females) selected from identified Drop-in centers under MSACS project in Aizawl City.

Design: To achieve the objectives, the study incorporated two-way classification of "Gender" (male and female) and three-way classification of "Level of IHS" (High IHS, Moderate IHS and Low IHS) on the dependent variables was employed.

Tools: The assessment battery consisted of the following:

i) Socio-Demographics: An interview schedule was used to find out and record the socio-demographic profile of the subjects like their age, gender, time of diagnosis, religion, educational qualification, occupation, income, marital status and number of children.

ii) Current Health Status: Participants rated their current health status according to a five-category index: $1=$ HIV-positive, with no symptoms. 2 = I have symptoms, but have not had to change my normal daily routines. 3 = I have symptoms that have required me to change parts of my normal routines of daily activities; extra rest is not required during a normal day. 4 = Because of my symptoms, I am in bed, or resting, less than half of my waking hours. 5 = Because of my symptoms, I am in bed, or resting, more than half of waking hours.

iii) The Internalized HIV Stigma Measure (Sayles et al., 2008): The Internalized HIV Stigma Measure is a 28-item scale that measures Internalized Stigma. The scale consists of 4 sub-scales, namely, Stereotypes of HIV, HIV Disclosure Concerns, Social Relationship Stigma and Self-Acceptance. Responses to each item are on a 5-point categorical response (none of the time, a little of the time, some of the time, most of the time, or all of the time). Total scores can range from $0-100$ with higher scores indicative of greater levels of internalized stigma. In this study, the overall stigma scores were categorized into three categories such as Low, moderate and high stigma using the $33^{\text {rd }}$ and $66^{\text {th }}$ percentile cut off values from the distribution of scores. This categorization was exclusively done for this study.

iv) Beck Depression Inventory-Second Edition (BDI-II) (Beck, Steer, \& Brown, 1996): This is a 21-item self-report instrument intended to assess the existence and severity of symptoms of depression as listed in the American Psychiatric Association's Diagnostic and Statistical Manual of Mental Disorders Fourth Edition (DSM-IV; 1994). Each of the 21 items corresponding to a symptom of depression is summed to give a single score for the BDI-II. There is a four-point scale for each item ranging from 0 to 3 . On two items (16 and 18) there are seven options to indicate either an increase or decrease of appetite and sleep. Cut score guidelines for the BDI-II are given with the recommendation that thresholds be adjusted based on the characteristics of the sample, and the purpose for use of the BDI-II. Total score of 0 - 13 is considered minimal range, 14 - 19 is mild, 20 - 28 is moderate, and 29 - 63 is severe.

v) Beck Anxiety Inventory (BAI) (Beck \& Steer, 1993): This is a 21-question multiple-choice self-report inventory that is used for measuring the severity of an individual's anxiety. It consists of questions about how the subject has been feeling in the last month, expressed as common symptoms of anxiety (such as numbness and tingling, sweating not due to heat, and fear of the worst happening). It is designed for an age range of 17 - 80 years old. Each question has the same set of four possible answer choices, which are arranged in columns and are answered by marking the appropriate one with a cross.

vi) The Coping Inventory for Stressful Situations (CISS; Endler \& Parker, 1990a): This is a 48 item inventory used to measure coping styles. The three scales include Task-Oriented coping (making alterations to solve the problem), Emotion-Oriented coping (managing emotions resulting from stress), and Avoidance-Oriented coping (attempting to avoid the stressor). The Avoidance-Oriented coping scale includes two subscales-the Distraction 
scale and the Social Diversion scale. Respondents indicate the frequency of use of several coping behaviors while in stressful situations, from 1 (not at all) to 5 (very much).

vii) The Multidimensional Scale of Perceived Social Support (Zimet et al., 1988): This 12-item scale measures perceived social support from family, friends and significant other. Respondents will use ratings along a 7-point scale, from 1 (very strongly disagree) to 7 (very strongly agree) to indicate how they feel about each statement. Total scores can range from 12 to 84, with total scores of 69-84 indicative of high acuity, 49-68 indicative of moderate acuity and 12 to 48 indicative of low acuity.

Reliability of instruments: In the Internalized HIV Stigma Measure, the overall internal consistency (Cronbach's alpha) for the entire 28-item scale was 0.87. The Cronbach's alpha for Stereotypes of HIV, HIV Disclosure Concerns, Social Relationship Stigma and Self-Acceptance was 0.84, 0.93, 0.72 and 0.57 respectively. In the Beck Depression Inventory—Second edition (BDI-II), the Cronbach's alpha was 0.90, while the Cronbach's alpha for Beck Anxiety Inventory (BAI) was 0.93. The overall internal consistency (Cronbach's alpha) for the Coping Inventory for Stressful Situations (CISS) for the entire 48-item scale was 0.91. the Cronbach's alpha for subscales Task, Emotion and Avoidance was 0.84, 0.83 and 0.80 respectively. In the Multidimensional Scale of Perceived Social Support, the overall internal consistency (Cronbach's alpha) for the entire 12-item scale was 0.82. The Cronbach’s alpha for Significant others, Family and Friends was 0.71, 0.95 and 0.85 respectively. (Table 1).

Analysis of data: Data were analyzed using the SPSS software (version 19). Descriptive analyses were conducted to examine the population characteristics and the prevalence of Internalized Stigma among PLWHA in Aizawl. In addition, Mann Whitney U test and Kruskal Wallis Chi-Square test were employed to find the differences in Internalized HIV Stigma based on socio-demographic variables (age, gender, duration of diagnosis, church denomination, marital status, number of children, educational qualification, occupation and income). Further, Spearman's rank order correlation coefficients was employed to examine correlations between the four subscales of Internalized HIV Stigma and Anxiety, Depression, three subscales of Coping and Perceived Social Support.

\section{Results}

\subsection{Demographic Characteristics of PLWHAs}

Table 2 and Table 3 present the socio-demographic characteristics of 31 PLWHA. The study included 13 (41.9\%)

\begin{tabular}{lc} 
Table 1. Reliability and internal consistency of tools. \\
\hline Scale/Subscale & Cronbach's Alpha \\
\hline Internalized HIV Stigma Measure & 0.87 \\
Stereotypes of HIV & 0.84 \\
HIV Disclosure Concerns & 0.93 \\
Social Relationship Stigma & 0.72 \\
Self-acceptance & 0.57 \\
Beck Depression Inventory (BDI)-II & 0.90 \\
Beck Anxiety Inventory (BAI) & 0.93 \\
Coping Inventory for Stressful Situations (CISS) & 0.91 \\
Task & 0.84 \\
Emotion & 0.83 \\
Avoidance & 0.80 \\
Multidimensional Scale of Perceived Social Support & 0.82 \\
Significant Others & 0.72 \\
Family & 0.96 \\
Friends & 0.85 \\
\hline
\end{tabular}


males and 18 (58.1\%) females, aged between 20 and 40 years. 13 (41.9\%) subjects were of the age group, 26 to 30 years. Among 31 PLWHA, 10 (32.3\%) had been diagnosed with HIV or AIDS in the year prior to the interview, $14(45.2 \%)$ in the past two to four years, 5 (16.1\%) in the past five to eight years, while only 2 (6.5\%) subjects had been diagnosed nine to ten years ago. All the participants in the study were Christians, and so their church denominations were specified, with 71\% of them Presbyterian. More than half of the participants (51.6\%) were married and 22 (71\%) subjects had children (Table 2). Regarding their Educational Qualification, 15 (48.4\%) had studied till High School and 2 (6.5\%) were illiterate, while only 2 (6.5\%) were graduates. Among the 31 participants, 35.5\% were unemployed. Among those employed, 38\% were manual laborers. 12 (38.7\%) subjects had no regular income, while among those with regular income, the highest percentage (25.8\%) earned between Rs. 3000 and 6000 (Table 3).

Among the 31 participants in the study, 10 (32.3\%) of them had experienced no symptoms, while 10 (32.3\%) had symptoms but had no change in normal daily routines. 6 (19.4\%) reported having symptoms that had required changes in parts of normal routines of daily activities, and 5 (16.1\%) were in bed, or resting, less than half of waking hours due to symptoms. None of the participants reported being in bed more than half of their waking hours (Table 4).

Table 2. Age, gender, duration of diagnosis, church denomination, marital status and number of children of PLWHA.

\begin{tabular}{|c|c|}
\hline Age & Frequency (Percent) \\
\hline 20 to 25 years & $6(19.4 \%)$ \\
\hline 26 to 30 years & 13 (41.9\%) \\
\hline 31 to 35 years & $6(19.4 \%)$ \\
\hline 36 to 40 years & $6(19.4 \%)$ \\
\hline \multicolumn{2}{|l|}{ Gender } \\
\hline Male & 13 (41.9\%) \\
\hline Female & $18(58.1 \%)$ \\
\hline \multicolumn{2}{|c|}{ Duration of Diagnosis } \\
\hline$>$ or $=1$ year & $10(32.3 \%)$ \\
\hline 2 to 4 years & $14(45.2 \%)$ \\
\hline 5 to 8 years & $5(16.1 \%)$ \\
\hline 9 to 10 years & $2(6.5 \%)$ \\
\hline \multicolumn{2}{|c|}{ Church Denomination } \\
\hline Presbyterian & $22(71 \%)$ \\
\hline Seventhday & $1(3.2 \%)$ \\
\hline Baptist & $5(16.1 \%)$ \\
\hline UPC & $1(3.2 \%)$ \\
\hline Salvation & 2 (6.5\%) \\
\hline \multicolumn{2}{|l|}{ Marital Status } \\
\hline Single & $4(12.9 \%)$ \\
\hline Married & $16(51.6 \%)$ \\
\hline Divorced & $8(25.8 \%)$ \\
\hline Widowed & 3 (9.7\%) \\
\hline \multicolumn{2}{|c|}{ Number of Children } \\
\hline 0 & $9(29 \%)$ \\
\hline 1 & $10(32.3 \%)$ \\
\hline 2 & $5(16.1 \%)$ \\
\hline 3 & $4(12.9 \%)$ \\
\hline 4 & 2 (6.5\%) \\
\hline 5 & $1(3.2 \%)$ \\
\hline
\end{tabular}


Table 3. Educational qualification, occupation and income of PLWHA.

\begin{tabular}{|c|c|}
\hline Educational Qualification & Frequency (Percent) \\
\hline Illiterate & $2(6.5 \%)$ \\
\hline Primary school & $1(3.2 \%)$ \\
\hline Middle school & $7(22.6 \%)$ \\
\hline High school & 15 (48.4\%) \\
\hline Higher Secondary School & $4(12.9 \%)$ \\
\hline Graduate & $2(6.5 \%)$ \\
\hline \multicolumn{2}{|l|}{ Occupation } \\
\hline Unemployed & $11(35.5 \%)$ \\
\hline Manual labour & $9(29 \%)$ \\
\hline Driver & $3(9.7 \%)$ \\
\hline Self-employed & $1(3.2 \%)$ \\
\hline Teacher & $2(6.5 \%)$ \\
\hline Business & $3(9.7 \%)$ \\
\hline Social work & $1(3.2 \%)$ \\
\hline Tailor & $1(3.2 \%)$ \\
\hline \multicolumn{2}{|l|}{ Monthly Income } \\
\hline no income & $12(38.7 \%)$ \\
\hline Below 3000 & $4(12.9 \%)$ \\
\hline Between 3000 and 6000 & $8(25.8 \%)$ \\
\hline Between 6000 and 9000 & $4(12.9 \%)$ \\
\hline Between 9000 and 12000 & $2(6.5 \%)$ \\
\hline Above 12000 & $1(3.2 \%)$ \\
\hline
\end{tabular}

Table 4. Current health status of PLWHA.

\begin{tabular}{lcc}
\hline Current Health Status & Frequency & Percent \\
\hline $\begin{array}{l}\text { HIV-positive, with no symptoms } \\
\text { Have symptoms, but no change in normal daily routines }\end{array}$ & 10 & 32.3 \\
$\begin{array}{l}\text { Have symptoms that have required changes in parts of normal routines of } \\
\text { daily activities }\end{array}$ & 6 & 19.3 \\
$\begin{array}{l}\text { In bed, or resting, less than half of waking hours due to symptoms } \\
\text { In bed, or resting, more than half of waking hours }\end{array}$ & 5 & 16.1 \\
\hline
\end{tabular}

Internalized HIV Stigma among PLWHA in Aizawl: The level of IHS among PLWHA is presented in Table 5. None of the participants' scores fell in the High level of IHS. 20 subjects (9 males and 11 females) fall under the moderate level of IHS, while 11 (4 males and 7 females) fall under the low IHS level. The mean IHS score was found to be 41.07 and SD 16.66. The scores on the four subscales of the IHS Measure were also categorized into three levels (Low, moderate and high IHS). In the subscale Stereotypes of HIV, 20 subjects (8 males and 12 females) fall under the moderate level. In the subscale HIV Disclosure Concerns, 11 subjects (6 males and 5 females) fall under the moderate level. In the subscale Social Relationships stigma, no participant falls under the high level as was the case in Overall IHS score, while 23 (8 males and 15 females) fall under the low level. In the subscale Self-acceptance, 15 (7 males and 8 females) fall under the moderate level (Table 5).

Statistical analysis shows that there is no significant difference in IHS, on the basis of any of the socio-demographic variables. However, analysis of the different subscales revealed a significant difference in Social relationships stigma based on Current Health status ( $<$ 0.05) (Table 6).

Mental Health, Coping and Perceived Social Support among PLWHA in Aizawl: The Mental Health of 
Table 5. Prevalence and levels of internalized HIV stigma among PLWHA.

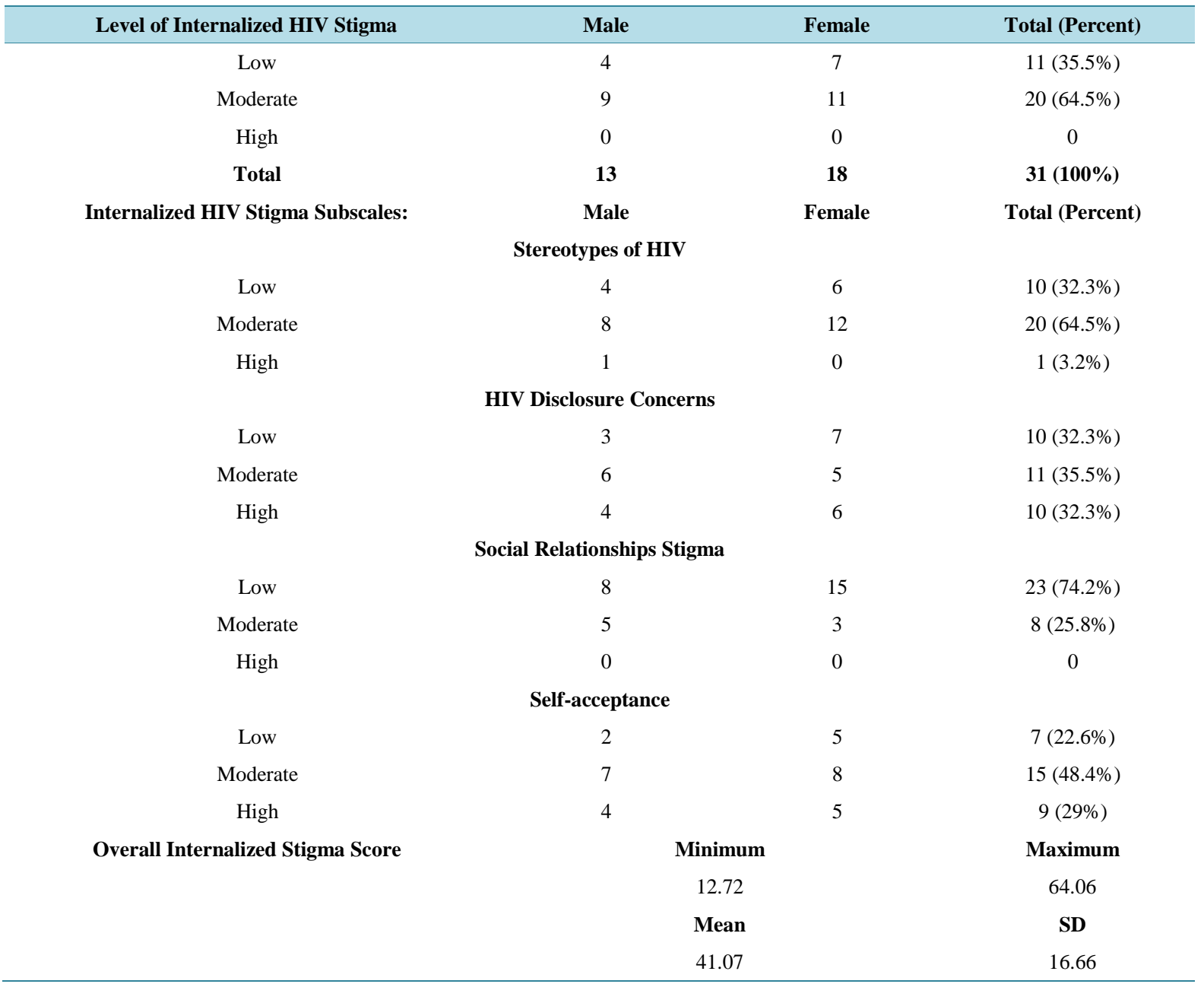

Table 6. Social relationships stigma and current health status.

\begin{tabular}{lcc}
\hline Social Relationships Stigma & $\begin{array}{c}\text { Low stigma } \\
\text { Moderate } \\
\text { Stigma }\end{array}$ & $\begin{array}{c}\text { Chi Square } \\
\text { p value }\end{array}$ \\
Current Health Status & 8 \\
HIV-positive, with no symptoms & 4 & 2 \\
Have symptoms, but no change in normal daily routines & 6 & 6 \\
Have symptoms that have required changes in parts of normal routines of daily activities & 5 & 0 \\
In bed, or resting, less than half of waking hours due to symptoms & 0 & 0 \\
In bed, or resting, more than half of waking hours &
\end{tabular}

the participants in this study was highlighted by measuring their level of depression and anxiety. The level of Depression, Anxiety and Perceived Social Support among PLWHA is presented in Table 7.7 subjects (1 males and 6 females) report severe depression while 11 (4 males and 7 females) report having moderate depression. The mean Depression score was found to be 21.35 and SD 10.84 . Only 13 subjects (4 males and 9 females) report severe anxiety, while 9 subjects (4 males and 5 females) report moderate anxiety. The mean Anxiety score was found to be 21.97 and SD 13.02. The coping strategies used by the subjects was analyzed and found that most of them (17/31) scored higher in the subscale Emotion, while 11 out of 31 subjects scored higher in the subscale Avoidance, and only 1 out of 31 subjects scored higher in the subscale Task. With regard to perceived 
Table 7. Depression, anxiety, coping and perceived social support among PLWHA.

\begin{tabular}{lccc}
\hline Levels of Depression & Male & Female & Total \\
\hline Minimal Depression & 5 & 2 & $7(22.6 \%)$ \\
Mild Depression & 3 & 3 & $6(19.4 \%)$ \\
Moderate Depression & 4 & 7 & $11(35.5 \%)$ \\
Severe Depression & 1 & 6 & $7(22.6 \%)$ \\
Levels of Anxiety & & $5(16.1 \%)$ \\
Minimal Anxiety & 4 & 1 & $4(12.9 \%)$ \\
Mild Anxiety & 1 & 3 & $9(29 \%)$ \\
Moderate Anxiety & 4 & 5 & $13(41.9 \%)$ \\
Severe Anxiety & 4 & 9 & $3(9.7 \%)$ \\
Levels of Perceived Social Support & & & $17(54.8 \%)$ \\
Low acuity & 1 & 2 & $11(35.5 \%)$ \\
Moderate acuity & 9 & 8 & $1(0.31 \%)$ \\
High acuity & 3 & 8 & $17(54.8 \%)$ \\
High scores in Subscales of Coping & & 1 & $11(35.5 \%)$ \\
Task & 0 & 13 & 7 \\
Emotion & 4 & & \\
Avoidance & 4 & & \\
\hline
\end{tabular}

social support, 11 subjects ( 3 males and 8 females) report high acuity, while 17 subjects ( 9 males and 8 females) report moderate acuity. The mean Perceived Social Support score was found to be 64.71 and SD 12.82 (Table 7).

Further analysis revealed significant gender differences in depression $(\mathrm{p}<0.05)$. It was also found that females scored higher in Emotion-oriented coping $(\mathrm{p}<0.05)$. However, when three-way classification of "Level of HIS" (High IHS, Moderate IHS and Low IHS) on the dependent variables was employed, no significant differences were found.

\subsection{Internalized HIV Stigma, Mental Health, Coping and Perceived Social Support}

Table 8 shows the correlation coefficients between Internalized HIV Stigma, Mental Health, Coping and Perceived Social Support of PLWHA. No significant relationship was found between Overall Internalized HIV stigma of PLWHA, Mental Health, Coping and Perceived Social Support. Depression and Anxiety were, however, significantly and negatively correlated $(\mathrm{p}<0.01)$.

Correlation coefficients between the four subscales of the Internalized HIV Stigma Measure and Anxiety, Depression, Coping and Perceived Social Support were also analyzed. Stereotypes of HIV was significantly and positively correlated with Anxiety $(\mathrm{p}<0.05)$. Social Relationships Stigma was also significantly and positively correlated with Anxiety $(\mathrm{p}<0.01)$ and Task-oriented Coping $(\mathrm{p}<0.05)$, and negatively with Perceived Social Support $(\mathrm{p}<0.05)$. However, no significant relationships were found between the subscales HIV Disclosure Concerns and Self-acceptance with Anxiety, Depression, Coping or Perceived Social Support.

The overall Internalized Stigma scores were significantly and positively correlated with its four subscales. Further analysis between the subscales of Internalized Stigma revealed positive correlation between Stereotypes of HIV and Social relationships stigma ( $<<0.01$ ), HIV Disclosure Concerns and Social Relationships Stigma (p $<0.01$ ) and HIV Disclosure Concerns and Self-acceptance $(\mathrm{p}<0.01)$. Emotion-oriented coping and Avoidanceoriented coping were also found to be significantly and positively correlated $(\mathrm{p}<0.01)$.

\section{Discussion}

This was a pilot study among PLWHA in Aizawl to determine the level of IHS and the association between stigma, mental health, coping and perceived social support. This is one of the first studies on PLWHA on the 
Table 8. Spearman’s correlation coefficients among internalized hiv stigma, mental health and perceived social support.

\begin{tabular}{|c|c|c|c|c|c|c|c|c|c|c|}
\hline & 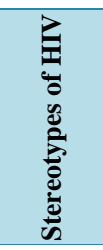 & 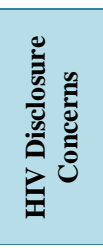 & 预 & 苋 & 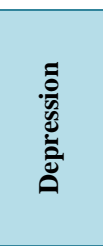 & 总 & ن & 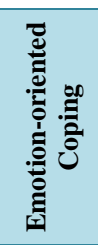 & 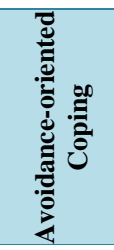 & 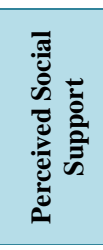 \\
\hline Internalized HIV Stigma & $0.555^{* *}$ & $0.882^{* *}$ & $0.650^{* *}$ & $0.623^{* *}$ & 0.172 & 0.115 & 0.179 & 0.108 & -0.143 & -0.182 \\
\hline Stereotypes of HIV & & 0.309 & $0.519^{* *}$ & 0.022 & 0.212 & $0.419^{*}$ & -0.07 & 0.189 & -0.124 & -0.062 \\
\hline HIV Disclosure Concerns & & & $0.357^{*}$ & $0.571^{* *}$ & 0.224 & -0.03 & 0.05 & 0.11 & -0.056 & -0.113 \\
\hline Social Relationships Stigma & & & & 0.199 & 0.035 & $0.467^{* *}$ & $0.652^{*}$ & -0.192 & -0.268 & $-0.379^{*}$ \\
\hline Self-Acceptance & & & & & -0.043 & -0.253 & -0.083 & -0.306 & -0.111 & 0.024 \\
\hline Depression & & & & & & $0.475^{* *}$ & -0.404 & 0.08 & 0.165 & 0.128 \\
\hline Anxiety & & & & & & & 0.184 & 0.399 & 0.391 & 0.097 \\
\hline Task-oriented Coping & & & & & & & & -0.028 & 0.003 & -0.407 \\
\hline Emotion-oriented Coping & & & & & & & & & $0.803^{* *}$ & 0.068 \\
\hline Avoidance-oriented Coping & & & & & & & & & & 0.452 \\
\hline
\end{tabular}

psychosocial aspects of stigma in the population. It is important to note that, from interviews with each of the participants, quite a large number of them had disclosed their HIV status only to health practitioners and counselors in the various NGOs which catered to their needs. Only a few of them had disclosed their HIV status to their whole network of family and friends, with some not disclosing their HIV status to anyone, while some had disclosed their status to only their spouses/parents.

This study found no presence of high IHS, with more than half of the subjects (64.5\%) falling under the moderate level of IHS, and 35.5\% under the low IHS level. This finding contradicts previous reports of IHS being high (between 63\% and 83\%) in studies conducted in Chennai and Bangalore (Thomas et al., 2005; Subramanian, Gupte, Dorairaj, Periannan, \& Mathai, 2009). However, further analysis of the subscales revealed high IHS levels in HIV Disclosure Concerns (32.3\%) and Self-acceptance (29\%). This is supported by quantitative studies of stigma (Subramanian et al., 2009; Thomas et al., 2005).

In this study, no significant differences in IHS have been found on the basis of any of the socio-demographic variables; however, Social Relationships Stigma has been found to differ according to the Current Health Status of PLWHA. These findings are supported by the findings of Lee, Kochman \& Sikkema (2002) in the United States, where no significant differences in IHS were found in terms of both age and gender, and IHS was positively correlated with Current Health Status. Analysis revealed significant gender differences in depression (p < 0.05), with women scoring higher, a finding that is supported by other studies (Moneyham, Sowell, Seals \& Demi, 2000). The current study also found that females scored higher in Emotion-oriented coping ( $<<0.05)$. This finding is supported by that of a study by Ptacek, Smith \& Dodge (1994), where women reported using emotion-focused coping to a greater extent than men.

Two subscales of IHS, Stereotypes of HIV and Social Relationships stigma were found to be significantly and positively correlated with anxiety, i.e., the higher the stigma in Stereotypes of HIV and Social Relationships, the higher the anxiety, and vice versa. This finding is supported by that of Lee, Kochman \& Sikkema, 2002, who established IHS as a significant predictor of anxiety and hopelessness. Also, the presence of severe anxiety in $41.9 \%$ of participants in this study is supported by a study conducted in India, where depression was present in $40 \%$ and anxiety in 36\% of the sample of 51 HIV-infected heterosexuals (Chandra, Ravi, Desai, \& Subbakrishna, 1998).

The examination of coping strategies used by PLWHA in this study revealed that most of the participants employed Emotion-oriented coping, and a few employed Avoidance-oriented coping. This study has not established any significant correlation between Overall IHS, Depression, Anxiety, Coping and Perceived Social Support. However, the absence of high IHS and less severe depression (22.6\%) reported by the subjects may fall along the lines of the findings of Crandall \& Coleman (1992), who found that among PLWHA, those who felt 
stigmatized also felt depressed and alienated from others. Further, the moderate (54.8\%) and high (35.5\%) perceived social support reported by the subjects may reveal that it plays a key role in buffering the negative effects of HIV-related stigma, as stated by Brouard \& Wills, 2006. Also, the findings that females scored higher both in depression and emotion-oriented coping may support the finding of Coetzee \& Spangenberg (2003), who documented that problem-focused, active coping styles were superior to emotion-focused, passive coping styles, such as avoidance, in reducing psychological distress. It is hoped that further in-depth study with a larger sample may establish these findings significantly.

\section{Conclusions}

The PLWHA in this study experience moderate levels of Internalized HIV Stigma, depression and perceived social support, and low level of anxiety. It was also seen that majority employed emotion-oriented coping strategy. Socio-demographic variables have not been found to play any significant role on Internalized HIV Stigma; however, Social Relationships Stigma has been found to differ according to the Current Health Status of PLWHA. Further analysis revealed that women scored higher both in depression and emotion-oriented coping. This study has not established any significant correlation between Overall IHS, Depression, Anxiety, Coping and Perceived Social Support. However, further analysis revealed that the two subscales of the IHS measure i.e. Stereotypes of HIV and Social Relationships stigma were significantly and positively correlated with anxiety.

From interviews with the participants, the tool used to examine the coping strategies of the participants (CISS) was not found to be suitable for this particular population. This is due to the exclusion of substance-use coping and religious coping styles, which are expected to be the most common forms of coping among PLWHA in Aizawl. The non-inclusion of Mode of Infection and Status Disclosure in Socio-Demographic profile is also suggested to be changed in order to allow more in-depth analyses.

There are some limitations to this study. First, no causal relationships have been analyzed in this study. Second, the sampling procedure was dependent on the members of various PLWHA networks. The proportion of PLWHA who are not members of these networks, and those who have not disclosed their HIV status so far is unknown. In addition, PLWHA aged between 20 - 40 years, who provided informed consent and were not too sick to answer the questions alone were included in the study. Thus our findings may not represent the entire PLWHA in Aizawl. Furthermore, the findings in this study are limited in their generalizability due to the relatively few number of participants, the unequal representation of men and women, and the lack of a control group. Moreover, cause and effect cannot be determined, as the findings were based on co-relational data. Therefore, the lack of significance in many associations between Internalized HIV Stigma, Mental Health, Coping and Perceived Social Support measures may be due to the small sample size and should not be interpreted as non-existence of associations. In addition, the majority of the participants in this study were in-patients at hospitals due to HIV symptoms, and may differ significantly from those who are not hospitalized and those who do not seek outside help. There is a need to carry out another study with a large sample covering different hospitals and different networks of PLWHAs, in order to elaborate on the findings of this study.

Despite the limitations, the findings from our study confirm an association between HIV-related stigma (Stereotypes of HIV and Social Relationships stigma) and anxiety. It is important to recognize that the harmful effects of stigma may work not only through the visible effects of discrimination by others, but also through the internal perceptions, beliefs and emotions of the stigmatized person. There seems to be a need to conduct an indepth and more comprehensive study addressing the HIV-related stigma and social stigma in all its forms, and incorporation of the social and religious ethos of the population under study to identify and present a more robust picture of the issues and challenges so the concerned agencies can plan intervention strategies and programs to address them.

\section{References}

Alonzo, A. A., \& Reynolds, N. R. (1995). Stigma, HIV and AIDS: An Exploration and Elaboration of a Stigma Trajectory. Social Science and Medicine, 41, 303-315. http://dx.doi.org/10.1016/0277-9536(94)00384-6

Beck, A. T., \& Steer, R. A. (1993). BAI: Beck Anxiety Inventory Manua. New York: Psychological Corporation.

Beck, A. T., Steer, R. A., \& Brown, G. K. (1996). Beck Depression Inventory (2nd ed.). BDI II: Manual. New York: The Psychological Corporation.

Bharat, S., Aggleton, P., \& Tyrer, P. (2001). India: HIV and AIDS Related Discrimination, Stigmatization and Denial. Ge- 
neva: UNAIDS.

Bisschop, M. I., Kriegsman, D. M., Beekman, A. T., \& Deeg, D. J. (2004). Chronic Diseases and Depression: The Modifying Role of Psychosocial Resources. Social Science and Medicine, 59, 721-733. http://dx.doi.org/10.1016/j.socscimed.2003.11.038

Brandt, R. (2009). The Mental Health of People Living with HIV/AIDS in Africa: A Systematic Review. African Journal of AIDS Research, 8, 123-133. http://dx.doi.org/10.2989/AJAR.2009.8.2.1.853

Brouard, P., \& Wills, C. (2006). A Closer Look: The Internalization of Stigma Related to HIV. United States Agency for International Development (USAID) Publication. http://www.policyproject.com.

Brown, L., Trujillo, L., \& Macintyre, K (2001). Interventions to Reduce HIV Stigma: What Have We Learned? Horizons Population Council, 4-6.

Chandra, P. S., Ravi, V., Desai, A., \& Subbakrishna, D. K. (1998). Anxiety and Depression among HIV-Infected Heterosexuals-A Report from INDIA. Journal of Psychosomatic Research, 45, 401-409. http://dx.doi.org/10.1016/S0022-3999(98)00028-2

Chesney, M. A., \& Smith, A. W. (1999). Critical Delays in HIV Testing and Care: The Potential Role of Stigma. American Behavioral Scientist, 42, 1162-1174. http://dx.doi.org/10.1177/00027649921954822

Coetzee, M., \& Spangenberg, J. J. (2003). Coping and Quality of Life in People with HIV/AIDS: A Review. Acta Academica, 35, 205-222.

Crandall, C. S., \& Coleman, R. (1992). AIDS-Related Stigmatization and the Disruption of Social Relationships. Journal of Social and Personal Relationships, 9, 163-177. http://dx.doi.org/10.1177/0265407592092001

Crawford, A. M. (1996). Stigma Associated with AIDS: A Meta-Analysis. Journal of Apllied Social Psychology, 26, 398416. http://dx.doi.org/10.1111/j.1559-1816.1996.tb01856.x

Emlet, C. A. (2007). Experiences of Stigma in Older Adults Living with HIV/AIDS: A Mixed-Methods Analysis. AIDS Patient Care and STDs, 21, 740-752. http://dx.doi.org/10.1089/apc.2007.0010

Endler, N. S., \& Parker, J. D. A. (1990a). Coping Inventory for Stressful Situations (CISS): Manual. Toronto: Multi-Health Systems.

Friedland, J., Renwick, R., \& McColl, M. M. (1996). Coping and Social Support as Determinants of Quality of Life in HIV/ AIDS. AIDS Care: Psychological and Socio-Medical Aspects of AIDS/HIV, 8, 15-32.

http://dx.doi.org/10.1080/09540129650125966

Goffman, E. (1963). Stigma: Notes on the Management of Spoiled Identity. Englewood Cliffs, NJ: Prentice Hall.

Goldsmith, D. J., Brashers, D. E., Kosenko, K. A., \& O’Keefe, D. J. (2008). Social Support and Living with HIV: Findings from Qualitative Studies. In: T. Edgar, S. M. Noar, \& V. S. Freimuth (Eds.), Communication Perspectives on HIV/AIDS for the 21st Century (pp. 101-136). New York: Lawrence Erlbaum Associates.

Hasan, M. T., Nath, S. R., Khan, N. S., Akram, O., Gomes, T. M., \& Rashid, S. F. (2012). Internalized HIV/AIDS-Related Stigma in a Sample of HIV-Positive People in Bangladesh. Journal of Health, Population and Nutrition, 30, 22-30. http://dx.doi.org/10.3329/jhpn.v30i1.11272

Hays, R. B., Mumusick, L., Pollack, L., Hillard, R., Hoff, C., \& Coates, T. J. (1993). Disclosing Seropositivity to Significant others. AIDS, 7, 425-431. http://dx.doi.org/10.1097/00002030-199303000-00019

Herek, G. M. (1990). Illness, stigma, and AIDS. In P. T. Costa Jr., \& G. R. Van den Bos (Eds.), Psychological Aspects of Serious Illness: Chronic Conditions, Fatal Diseases, and Clinical Care (pp. 103-150). Washington DC: American Psychological Association.

Herek, G. M. (1999). AIDS and Stigma. American Behavioral Scientist, 42, 1106-1116.

Herek, G. M., Capitanio, J. P., \& Widaman, K. F. (2002). HIV-Related Stigma and Knowledge in the United States: Prevalence and Trends, 1991-1999. American Journal of Public Health, 92, 371-377. http://dx.doi.org/10.2105/AJPH.92.3.371

Jacobi, C. A., Atanga, P. N. J. I., Bin, L. K., Mbome, V. N., Akam, W., Bogner, J. R., Kropf, S., \& Malfertheiner, P. (2011). HIV/AIDS-Related Stigma Felt by People Living with HIV from Buea, Cameroon. AIDS Care: Psychological and SocioMedical Aspects of AIDS/HIV, 25, 173-180. http://dx.doi.org/10.1080/09540121.2012.701715

Johnston, D., Stall, R., \& Smith, K. (1995). Reliance by Gay Men and Intravenous Drug Users on Friends and Family for AIDS-Related Care. AIDS Care: Psychological and Socio-Medical Aspects of AIDS/HIV, 7, 307-319. http://dx.doi.org/10.1080/09540129550126533

Klitzman, R. (1997). Being Positive: The Lives of Men and Women with HIV. Chicago, IL: Ivan R. Dee.

Lee, R. S., Kochman, A., \& Sikkema, K. J. (2002). Internalized Stigma among People Living with HIV-AIDS. AIDS and Behavior, 6, 309-319. http://dx.doi.org/10.1023/A:1021144511957

Leserman, J., Jackson, E. D., Petitto, J. M., Golden, R. N., Silva, S. G., Perkins, D. O., et al. (1999) Progression to AIDS: 
The Effects of Stress, Depressive Symptoms, and Social Support. Psychosomatic Medicine, 61, 397-406. http://dx.doi.org/10.1097/00006842-199905000-00021

Link, B. G. (1987). Understanding Labelling Effects in the Area of Mental Disorders: An Assessment of the Effects of Expectations of Rejection. American Sociological Review, 52, 96-112. http://dx.doi.org/10.2307/2095395

Link, B. G., \& Phelan, J. C. (2001). Conceptualizing Stigma. Annual Review of Sociology, 27, 363-385. http://dx.doi.org/10.1146/annurev.soc.27.1.363

Mak, W. W., Poon, C. Y., Pun, L. Y., \& Cheung, S. F. (2007). Meta-Analysis of Stigma and Mental Health. Social Science and Medicine, 65, 245-261. http://dx.doi.org/10.1016/j.socscimed.2007.03.015

Mann, J., Tarantola, D. J. M., \& Netter, T. W. Eds. (1992). AIDS in the World. Cambridge, MA: Harvard University Press.

Mawar, N., \& Paranjape, R. S. (2002). Live and Let Live: Acceptance of People Living with HIV/AIDS in an Era Where Stigma and Discrimination Persist. ICMR Bulletin, 32, 105-114.

Moneyham, L., Sowell, R., Seals, B., \& Demi, A. (2000). Depressive Symptoms among African American Women with HIV Disease. Scholarly Inquires in Nursing Practice, 14, 9-39.

Novick, A. (1997). Stigma and AIDS: Three Layers of Damage. Journal of the Gay and Lesbian Medical Association, 1, 5360. http://dx.doi.org/10.1023/B:JOLA.0000007011.17392.fb

Panos Institute (1990). The 3rd Epidemic: Repurcussions of the Fear of AIDS. London: Panos Institute.

Peltzer, K., \& Ramlagan, S. (2011). Perceived Stigma among Patients Receiving Antiretroviral Therapy: A Prospective Study in KwaZulu-Natal, South Africa. AIDS Care: Psychological and Socio-Medical Aspects of AIDS/HIV, 23, 60-68. http://dx.doi.org/10.1080/09540121.2010.498864

Perdices, M., Dunbar, N., Grunseit, A., Hall, W., \& Cooper, D. A. (1992). Anxiety, Depression and HIV Related Symptomatology. Across the Spectrum of HIV Disease, 26, 560-566.

Prachakul, W., Grant, J. S., \& Keltner, N. L. (2007). Relationships among Functional Social Support, HIV-Related Stigma, Social Problem Solving, and Depressive Symptoms in People Living with HIV: A Pilot Study. Journal of the Association of Nurses in AIDS Care, 18, 67-76. http://dx.doi.org/10.1016/j.jana.2007.08.002

Ptacek, J. T., Smith, R. E., \& Dodge, K. L. (1994). Gender Differences in Coping with Stress: When Stressor and Appraisals Do Not Differ. Personality and Social Psychology Bulletin, 20, 421-430. http://dx.doi.org/10.1177/0146167294204009

Sayles, J. N., Hays, R. D., Sarkisian, C. A., Mahajan, A. P., Spritzer, K. L., \& Cunningham, W. E. (2008). Development and Psychometric Assessment of a Multidimensional Measure of Internalized HIV Stigma in a Sample of HIV-Positive Adults. AIDS and Behavior, 12, 748-758. http://dx.doi.org/10.1007/s10461-008-9375-3

Subramanian, T., Gupte, M., Dorairaj, V., Periannan, V., \& Mathai, A. (2009). Psycho-Social Impact and Quality of Life of People Living with HIV/AIDS in South India. AIDS Care: Psychological and Socio-Medical Aspects of AIDS/HIV, 21, 473-481. http://dx.doi.org/10.1080/09540120802283469

Sun, H., Zhang, J., \& Fu, X. (2007). Psychological Status, Coping, and Social Support of People Living with HIV/AIDS in Central China. Public Health Nursing, 24, 132-140. http://dx.doi.org/10.1111/j.1525-1446.2007.00617.x

Thomas, B. E., Rehman, F., Suryanarayanan, D., Josephine, K., Dilip, M., Dorairaj, V. S., \& Swaminathan, S. (2005). How Stigmatizing Is Stigma in the Life of People Living with HIV: A Study on HIV Positive Individuals from Chennai, South India. AIDS Care: Psychological and Socio-Medical Aspects of AIDS/HIV, 17, 795-801.

Vyavaharkar, M., Moneyham, L., Corwin, S., Saunders, R., Annang, L., \& Tavakoli, A. (2010). Relationships between Stigma, Social Support, and Depression in HIV-Infected African American Women Living in the Rural Southeastern United States. Journal of the Association of Nurses in AIDS Care, 21, 144-152. http://dx.doi.org/10.1016/j.jana.2009.07.008

Webster, M. (2011a). Dictionary: Stigma. http://www.merriam-webster.com/dictionary/stigma

Webster, M. (2011b). Dictionary: Stigma. http://www.merriam-webster.com/thesaurus/stigma

Zimet, G. D., Dahlem, N. W., Zimet, S. G., \& Farley, G. K. (1988). The Multidimensional Scale of Perceived Social Support. Journal of Personality Assessment, 52, 30-41. http://dx.doi.org/10.1207/s15327752jpa5201_2 


\title{
Appendices
}

\author{
A. The Variables of the Socio-Demographic Profile \\ 1. Age \\ 2. Gender \\ 3. Time of diagnosis \\ 4. Church Denomination \\ 5. Educational qualification \\ 6. Occupation \\ 7. Monthly Income \\ 8. Marital status \\ 9. Number of children
}

\section{B. Current Health Status}

Please rate your current health status according to the following index:

1 = HIV-positive, with no symptoms.

2 = I have symptoms, but have not had to change my normal daily routines.

3 = I have symptoms that have required me to change parts of my normal routines of daily activities; extra rest is not required during a normal day.

4 = Because of my symptoms, I am in bed, or resting, less than half of my waking hours.

5 = Because of my symptoms, I am in bed, or resting, more than half of waking hours.

C. The Internalized HIV Stigma Measure (Sayles et al., 2008)

\begin{tabular}{|c|c|c|c|c|c|c|}
\hline & Please fill in ONE response for each of the following statements: & $\begin{array}{l}\text { None of } \\
\text { the time }\end{array}$ & $\begin{array}{l}\text { A little of } \\
\text { the time }\end{array}$ & $\begin{array}{l}\text { Some of } \\
\text { the time }\end{array}$ & $\begin{array}{l}\text { Most of } \\
\text { the time }\end{array}$ & $\begin{array}{l}\text { All of } \\
\text { the time }\end{array}$ \\
\hline 1 & HIV is different than other diseases like cancer because people with HIV are judged & 1 & 2 & 3 & 4 & 5 \\
\hline 2 & People assume I have done something bad to get HIV & 1 & 2 & 3 & 4 & 5 \\
\hline 3 & Society looks down on people who have HIV & 1 & 2 & 3 & 4 & 5 \\
\hline 4 & People think that if you have HIV then you got what you deserve & 1 & 2 & 3 & 4 & 5 \\
\hline 5 & People blame me for having HIV & 1 & 2 & 3 & 4 & 5 \\
\hline 6 & People assume I slept around because I have HIV & 1 & 2 & 3 & 4 & 5 \\
\hline 7 & People think that if you have HIV you do not deserve to have children & 1 & 2 & 3 & 4 & 5 \\
\hline 8 & People are afraid to let someone with HIV adopt a child & 1 & 2 & 3 & 4 & 5 \\
\hline 9 & People think I am a bad person because I have HIV & 1 & 2 & 3 & 4 & 5 \\
\hline 10 & Medical providers assume people with HIV sleep around & 1 & 2 & 3 & 4 & 5 \\
\hline 11 & People lose their jobs because they have HIV & 1 & 2 & 3 & 4 & 5 \\
\hline 12 & People think you can't be a good parent if you have HIV & 1 & 2 & 3 & 4 & 5 \\
\hline 13 & I am concerned if I go to the HIV clinic someone I know might see me & 1 & 2 & 3 & 4 & 5 \\
\hline 14 & $\begin{array}{l}\text { I am concerned if I have physical changes from the HIV medicines people will know } \\
\text { I have HIV }\end{array}$ & 1 & 2 & 3 & 4 & 5 \\
\hline 15 & I am concerned if I go to an AIDS organization someone I know might see me & 1 & 2 & 3 & 4 & 5 \\
\hline 16 & I am concerned people will find out I have HIV by looking at my medical paperwork & 1 & 2 & 3 & 4 & 5 \\
\hline 17 & I am concerned that if I am sick people I know will find out about my HIV & 1 & 2 & 3 & 4 & 5 \\
\hline 18 & Nurses and doctors treat people who have HIV as if they are contagious & 1 & 2 & 3 & 4 & 5 \\
\hline 19 & Nurses and doctors dislike caring for patients with HIV & 1 & 2 & 3 & 4 & 5 \\
\hline 20 & I feel abandoned by family members because I have HIV & 1 & 2 & 3 & 4 & 5 \\
\hline 21 & People treat me as less than human now that I have HIV & 1 & 2 & 3 & 4 & 5 \\
\hline 22 & People avoid me because I have HIV & 1 & 2 & 3 & 4 & 5 \\
\hline 23 & People I am close to are afraid they will catch HIV from me & 1 & 2 & 3 & 4 & 5 \\
\hline 24 & I feel like I am an outsider because I have HIV & 1 & 2 & 3 & 4 & 5 \\
\hline
\end{tabular}




\section{Continued}

$\begin{array}{lllrr}25 & \text { I feel ashamed to tell other people that I have HIV } & 1 & 2 & 3 \\ 26 & \text { I am comfortable telling everyone I know that I have HIV } \ddagger & 1 & 2 & 3 \\ 27 & \text { My family is comfortable talking about my HIV } \ddagger & 1 & 2 & 3 \\ 28 & \text { It is important for a person to keep HIV a secret from co-workers } & 1 & 2 & 3\end{array}$

\section{Beck Depression Inventory—Second Edition (BDI-II) (Beck, Steer, \& Brown, 1996)}

Instructions: Please read each group of statements carefully, and then pick out the one statement in each group that best describes the way you have been feeling during the past two weeks, including today. Circle the number beside the statement you have picked. If several statements in the group seem to apply equally well, circle the highest number for that group. Be sure that you do not choose more than one statement for any group.

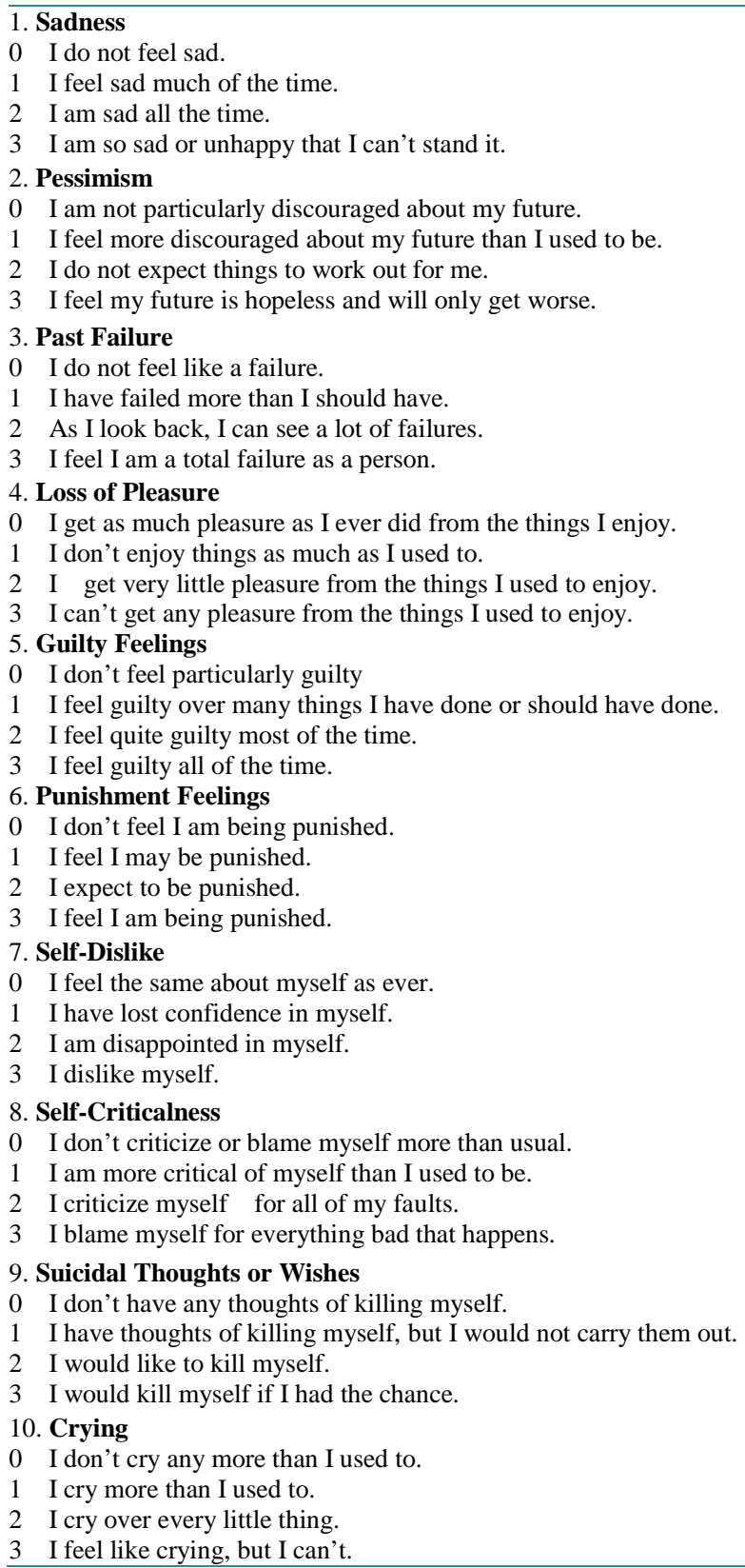




\section{Continued}

11. Agitation

0 I am no more restless or wound up than usual.

1 I feel more restless or wound up than usual.

2 I am so restless or agitated that it's hard to stay still.

3 I am so restless or agitated that it's I have to keep moving or doing something.

\section{Loss of Interest}

0 I have not lost interest in other people or activities.

1 I am less interested in other people or things than before.

2 I have lost most of my interest in other people or things.

3 It's hard to get interested in anything.

\section{Indecisiveness}

0 I make decisions about as well as ever.

1 I find it more difficult to make decisions than usual.

2 I have much greater difficulty in making decisions than I used to.

3 I have trouble making any decisions.

\section{Worthlessness}

0 I do not feel that I am worthless.

1 I don't consider myself as worthwhile and useful as I used to.

2 I feel more worthless as compared to other people.

3 I feel utterly worthless.

\section{Loss of Energy}

0 I have as much energy as ever.

1 I have less energy than I used to have.

2 I don't have enough energy to do very much.

3 I don't have enough energy to do anything.

\section{Changes in Sleeping Pattern}

0 I have not experienced any change in my sleeping pattern.

1a I sleep somewhat more than usual.

1b I sleep somewhat less than usual.

2a I sleep a lot more than usual.

2b I sleep a lot less than usual.

3a I sleep most of the day.

3b I wake up 1-2 hours early and can't get back to sleep.

\section{Irritability}

0 I am no more irritable than usual.

1 I am more irritable than usual.

2 I am much more irritable than usual.

3 I am irritable all the time.

\section{Changes in Appetite}

0 I have not experienced any change in my appetite.

1a My appetite is somewhat less than usual.

1b My appetite is somewhat greater than usual.

2a My appetite is much less than before.

2b My appetite is much greater than usual.

3a I have no appetite at all.

3b I crave food all the time.

\section{Concentration Difficulty}

0 I can concentrate as well as ever.

1 I can't concentrate as well as usual.

2 It's hard to keep my mind o anything for long.

3 I find I can't concentrate on anything.

\section{Tiredness or Fatigue}

0 I am no more tired or fatigued than usual.

1 I get tired or fatigued more easily than usual.

2 I am too tired or fatigued to do a lot of the things I used to do.

3 I am too tired or fatigued to do most of the things I used to do.

\section{Loss of Interest in Sex}

0 I have not noticed any recent change in my interest in sex.

1 I am less interested in sex than I used to be.

2 I am much less interested in sex now.

3 I have lost interest in sex completely. 


\section{E. Beck Anxiety Inventory}

\begin{tabular}{|c|c|c|c|c|}
\hline $\begin{array}{l}\text { Indicate how much you have been bothered by each } \\
\text { symptom during the past month, including today, by } \\
\text { circling the number in the corresponding space in the } \\
\text { column next to each symptom. }\end{array}$ & Not At All & $\begin{array}{l}\text { Mildly but it didn't } \\
\text { bother me much. }\end{array}$ & $\begin{array}{c}\text { Moderately—it } \\
\text { wasn't pleasant at } \\
\text { times }\end{array}$ & $\begin{array}{c}\text { Severely_it } \\
\text { bothered me a } \\
\text { lot }\end{array}$ \\
\hline Numbness or tingling & 0 & 1 & 2 & 3 \\
\hline Feeling hot & 0 & 1 & 2 & 3 \\
\hline Wobbliness in legs & 0 & 1 & 2 & 3 \\
\hline Unable to relax & 0 & 1 & 2 & 3 \\
\hline Fear of worst happening & 0 & 1 & 2 & 3 \\
\hline Dizzy or lightheaded & 0 & 1 & 2 & 3 \\
\hline Heart pounding/racing & 0 & 1 & 2 & 3 \\
\hline Unsteady & 0 & 1 & 2 & 3 \\
\hline Terrified or afraid & 0 & 1 & 2 & 3 \\
\hline Nervous & 0 & 1 & 2 & 3 \\
\hline Feeling of choking & 0 & 1 & 2 & 3 \\
\hline Hands trembling & 0 & 1 & 2 & 3 \\
\hline Shaky/unsteady & 0 & 1 & 2 & 3 \\
\hline Fear of losing control & 0 & 1 & 2 & 3 \\
\hline Difficulty in breathing & 0 & 1 & 2 & 3 \\
\hline Fear of dying & 0 & 1 & 2 & 3 \\
\hline Scared & 0 & 1 & 2 & 3 \\
\hline Indigestion & 0 & 1 & 2 & 3 \\
\hline Faint / lightheaded & 0 & 1 & 2 & 3 \\
\hline Face flushed & 0 & 1 & 2 & 3 \\
\hline Hot/cold sweats & 0 & 1 & 2 & 3 \\
\hline Column Sum & & & & \\
\hline
\end{tabular}

F. The Coping Inventory for Stressful Situations (CISS; Endler \& Parker, 1990a)

\begin{tabular}{|c|c|c|c|c|c|c|}
\hline & $\begin{array}{l}\text { Indicate how much you engage in these types of activities when you encounter a } \\
\text { difficult, stressful or upsetting situation. }\end{array}$ & Not at all & & & & $\begin{array}{l}\text { Very } \\
\text { much }\end{array}$ \\
\hline 1 & Schedule my time better. & 1 & 2 & 3 & 4 & 5 \\
\hline 2 & Focus on the problem and see how I can solve it. & 1 & 2 & 3 & 4 & 5 \\
\hline 3 & Think about the good times I've had. & 1 & 2 & 3 & 4 & 5 \\
\hline 4 & Try to be with other people. & 1 & 2 & 3 & 4 & 5 \\
\hline 5 & Blame myself for procrastinating.. & 1 & 2 & 3 & 4 & 5 \\
\hline 6 & Do what I think is best. & 1 & 2 & 3 & 4 & 5 \\
\hline 7 & Become preoccupied with aches and pains. & 1 & 2 & 3 & 4 & 5 \\
\hline 8 & Blame myself for having gotten into this situation. & 1 & 2 & 3 & 4 & 5 \\
\hline 9 & Window shop. & 1 & 2 & 3 & 4 & 5 \\
\hline 10 & Outline my priorities. & 1 & 2 & 3 & 4 & 5 \\
\hline 11 & Try to go to sleep. & 1 & 2 & 3 & 4 & 5 \\
\hline 12 & Treat myself to a favorite food or snack. & 1 & 2 & 3 & 4 & 5 \\
\hline
\end{tabular}




\section{Continued}

\begin{tabular}{|c|c|c|c|c|c|c|}
\hline 13 & Feel anxious about not being able to cope. & 1 & 2 & 3 & 4 & 5 \\
\hline 14 & Become very tense. & 1 & 2 & 3 & 4 & 5 \\
\hline 15 & Think about how I solved similar problems. & 1 & 2 & 3 & 4 & 5 \\
\hline 16 & Tell myself that it is not really happening to me. & 1 & 2 & 3 & 4 & 5 \\
\hline 17 & Blame myself for being too emotional about the situation. & 1 & 2 & 3 & 4 & 5 \\
\hline 18 & Go out for a snack or meal. & 1 & 2 & 3 & 4 & 5 \\
\hline 19 & Become very upset. & 1 & 2 & 3 & 4 & 5 \\
\hline 20 & Buy myself something. & 1 & 2 & 3 & 4 & 5 \\
\hline 21 & Determine a course of action and follow it. & 1 & 2 & 3 & 4 & 5 \\
\hline 22 & Blame myself for not knowing what to do. & 1 & 2 & 3 & 4 & 5 \\
\hline 23 & Go to a party. & 1 & 2 & 3 & 4 & 5 \\
\hline 24 & Work to understand the situation. & 1 & 2 & 3 & 4 & 5 \\
\hline 25 & "Freeze" and not know what to do. & 1 & 2 & 3 & 4 & 5 \\
\hline 26 & Take corrective action immediately. & 1 & 2 & 3 & 4 & 5 \\
\hline 27 & Think about the event and learn from my mistakes. & 1 & 2 & 3 & 4 & 5 \\
\hline 28 & Wish that I could change what had happened or how I felt. & 1 & 2 & 3 & 4 & 5 \\
\hline 29 & Visit a friend. & 1 & 2 & 3 & 4 & 5 \\
\hline 30 & Worry about what I am going to do. & 1 & 2 & 3 & 4 & 5 \\
\hline 31 & Spend time with a special person. & 1 & 2 & 3 & 4 & 5 \\
\hline 32 & Go for a walk. & 1 & 2 & 3 & 4 & 5 \\
\hline 33 & Tell myself that it will never happen again. & 1 & 2 & 3 & 4 & 5 \\
\hline 34 & Focus o my general inadequacies. & 1 & 2 & 3 & 4 & 5 \\
\hline 35 & Talk to someone whose advice I value. & 1 & 2 & 3 & 4 & 5 \\
\hline 36 & Analyze the problem before reacting. & 1 & 2 & 3 & 4 & 5 \\
\hline 37 & Phone a friend. & 1 & 2 & 3 & 4 & 5 \\
\hline 38 & Get angry. & 1 & 2 & 3 & 4 & 5 \\
\hline 39 & Adjust my priorities. & 1 & 2 & 3 & 4 & 5 \\
\hline 40 & See a movie. & 1 & 2 & 3 & 4 & 5 \\
\hline 41 & Get control of the situation. & 1 & 2 & 3 & 4 & 5 \\
\hline 42 & Make an extra effort to get things done. & 1 & 2 & 3 & 4 & 5 \\
\hline 43 & Come up with several different solutions to the problem. & 1 & 2 & 3 & 4 & 5 \\
\hline 44 & Take some time off and get away from the situation. & 1 & 2 & 3 & 4 & 5 \\
\hline 45 & Take it out on other people. & 1 & 2 & 3 & 4 & 5 \\
\hline 46 & Use the situation to prove that I can do it. & 1 & 2 & 3 & 4 & 5 \\
\hline 47 & Try to be organized so I can be on top of the situation. & 1 & 2 & 3 & 4 & 5 \\
\hline 48 & Watch TV. & 1 & 2 & 3 & 4 & 5 \\
\hline
\end{tabular}


G. Multidimensional Scale of Perceived Social Support (Zimet, Dahlem, Zimet, \& Farley, 1988)

\begin{tabular}{|c|c|c|c|c|c|c|c|c|}
\hline & $\begin{array}{l}\text { We are interested in how you feel about the following statements. Read } \\
\text { each statement carefully. Indicate how you feel about each statement. }\end{array}$ & 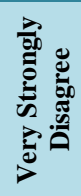 & 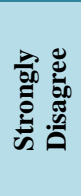 & 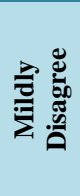 & ż & 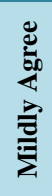 & 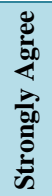 & 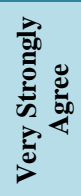 \\
\hline 1 & There is a special person who is around when I am in need. & 1 & 2 & 3 & 4 & 5 & 6 & 7 \\
\hline 2 & There is a special person with whom I can share my joys and sorrows. & 1 & 2 & 3 & 4 & 5 & 6 & 7 \\
\hline 3 & My family really tries to help me. & 1 & 2 & 3 & 4 & 5 & 6 & 7 \\
\hline 4 & I get the emotional help and support I need from my family. & 1 & 2 & 3 & 4 & 5 & 6 & 7 \\
\hline 5 & I have a special person who is a real source of comfort to me. & 1 & 2 & 3 & 4 & 5 & 6 & 7 \\
\hline 6 & My friends really try to help me. & 1 & 2 & 3 & 4 & 5 & 6 & 7 \\
\hline 7 & I can count on my friends when things go wrong. & 1 & 2 & 3 & 4 & 5 & 6 & 7 \\
\hline 8 & I can talk about my problems with my family. & 1 & 2 & 3 & 4 & 5 & 6 & 7 \\
\hline 9 & I have friends with whom I can share my joys and sorrows. & 1 & 2 & 3 & 4 & 5 & 6 & 7 \\
\hline 10 & There is a special person in my life who cares. & 1 & 2 & 3 & 4 & 5 & 6 & 7 \\
\hline 11 & My family is willing to help me make decisions. & 1 & 2 & 3 & 4 & 5 & 6 & 7 \\
\hline 12 & I can talk about my problems with my friends. & 1 & 2 & 3 & 4 & 5 & 6 & 7 \\
\hline
\end{tabular}


Scientific Research Publishing (SCIRP) is one of the largest Open Access journal publishers. It is currently publishing more than 200 open access, online, peer-reviewed journals covering a wide range of academic disciplines. SCIRP serves the worldwide academic communities and contributes to the progress and application of science with its publication.

Other selected journals from SCIRP are listed as below. Submit your manuscript to us via either submit@scirp.org or Online Submission Portal.
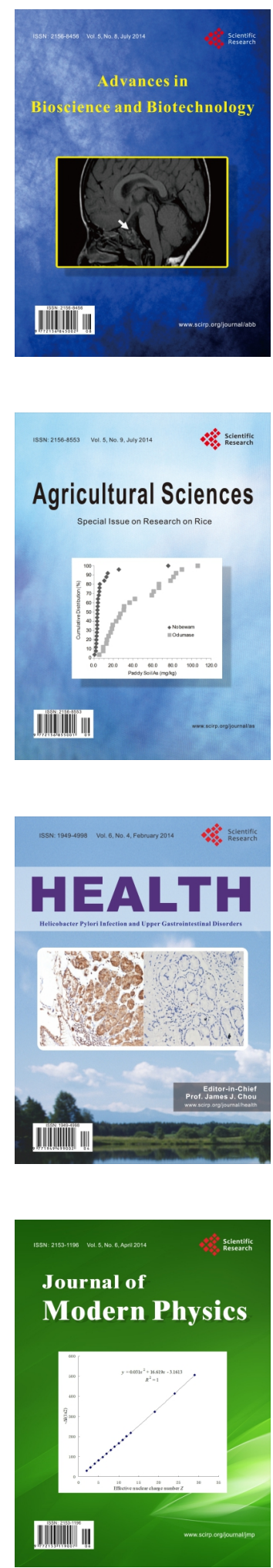
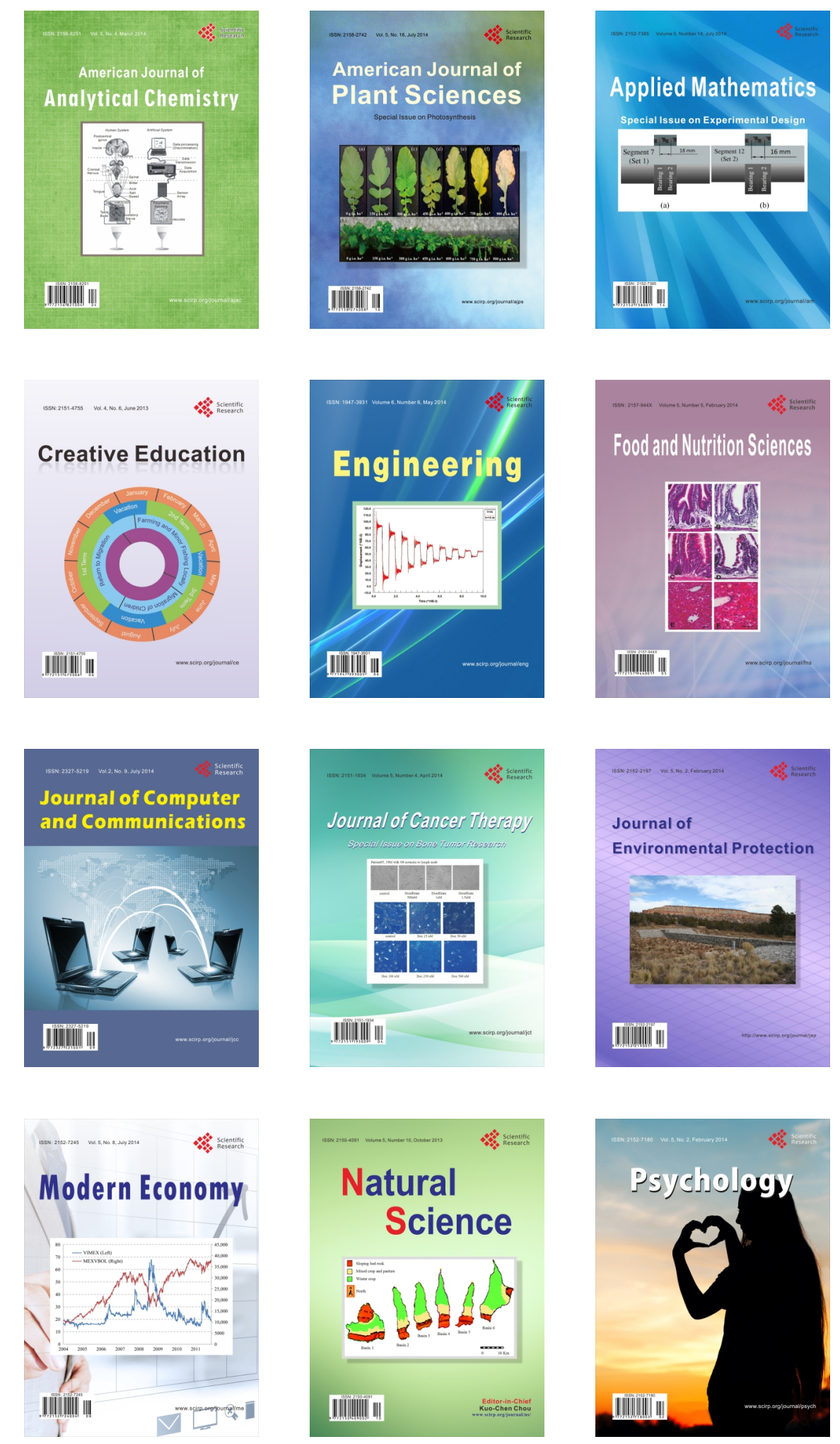